\title{
Boom and Bust Cycle of the Stock Market, and Economic Growth in a Vintage Capital Model ${ }^{\$}$
}

\author{
Takeshi Kobayashi ${ }^{*}$ and Masaya Sakuragawa ${ }^{* *}$
}

We construct a growth model of overlapping generations with vintage capital. There exists an equilibrium that converges to the balanced growth path through endogenous fluctuations of investment, consumption, and output in terms of the growth rate. When the technological change arrives and a rise in productivity is embodied only in newly invested capital, the economy converges to a new balanced growth path with a higher growth rate of output, but when we interpret the price of existing old capital as the stock market capitalization, the rise in productivity is accompanied by an initial decline in the stock market. Oscillatory equilibria are supported as perfect-foresight equilibria in the present framework with finitely lived agents and capital. Any oscillatory equilibrium is associated with the regime switch from an economy with both young and old capital in use into the one with only old capital in use.

Keyword: Economic Growth, Vintage Capital, Technological Change.

JEL Classification: E13, E32, O33, O47.

\footnotetext{
\$ We are greatly thankful to Kaoru Hosono, Hidehiko Ishihara, Boyan Jovanovic, Yukie Sakuragawa, Tadashi Shigoka, Noriyuki Yanagawa, and especially an anonymous referee for valuable comments. * Department of Economics, Chukyo University, Nagoya, JAPAN, takeshi@mecl.chyukyo-u.ac.jp

** Department of Economics, Keio University, Tokyo, JAPAN. masaya@econ.keio-cu.ac.jp.
} 


\section{Introduction}

We construct a growing version of Diamond's (1965) overlapping generations model with vintage capital. The idea of vintage capital is motivated by the insight on the recent technological progress, called the "IT revolution," that is supposed to have started with the invention of the microprocessor around 1973. The new technology did not diffuse equally among all firms, but favored newly established firms over incumbent ones [e.g. Hobjin and Jovanovic (2001)]. We think that the vintage capital model can describe well a situation in which a rise in productivity is embodied only in newly invested capital, not in existing old capital. $^{1}$

The main departure from the Diamond model is that capital does not depreciate exponentially and is periodically replaced. ${ }^{2}$ In particular, we assume that capital depreciates fully after two periods. We consider this assumption plausible. Setting the annual depreciation of capital to be $10 \%$, capital survives by about $12.2 \%$ after twenty years, but only about $1.5 \%$ after forty years.

At any instant of time, at most two types of capital, "young" capital and "old" capital, are in use. There exists an equilibrium that converges to the balanced-growth path through endogenous fluctuations of investment, consumption, and output in terms of the growth rate. A greater investment in new capital of the current period implies a greater stock of old capital purchased by agents of the next generation at the end of the subsequent period, which in turn tends to crowd out new capital investment by the next generation. The counter-cyclical behavior between new capital investments of the two successive periods is the driving force of endogenous fluctuations of economic growth. ${ }^{3}$

\footnotetext{
${ }^{1}$ A number of vintage-capital models describe the process of "creative destruction" associated with technological progress, including those of Caballero and Hammour (1994)(1996), Boldrin and Levine (2001), Greenwood et al (1997), Hobjin and Jovanovic (2001), and Laitner and Stolyarov (2003).

${ }^{2}$ Although we focus on vintage of physical capital in this paper, we observe other types of vintage capital models. Chari and Hopenhayn (1991) develop a model allowing for complementarity between experienced and inexperienced workers in order to explain the empirically observed gradual diffusion of technology. Fershtman, Murphy, and Weiss (1996), and Kremer and Thomson (1998) construct growth models allowing for complementarity between different vintages of human capital. ${ }^{3}$ Many vintage capital models derive the cyclical behavior of economic activities, including Benhabib and Rustichini (1991), Caballero and Hammour (1994), Boucekkine, et al (1999), and others. Benhabib and Rustichini (1991) study how nonexponential depreciation of capital can lead to
} 
We investigate the effects of technological change on the price of old capital and economic growth. As we often observe in the information technology (IT) industries, we consider a situation in which technological progress is embodied only in new capital investment. The unequal diffusion of new technology leads not only to improvement of the productivity of new capital but also to the acceleration of endogenous obsolescence of old capital. The stock market capitalization, defined by market values of old capital relative to GNP, initially declines. The perverse behavior of the stock market disappears in the long run, and the economy finally attains faster growth with a higher level of stock market capitalization. The technological change accelerates economic growth accompanied by faster depreciation of existing capital.

The impact of the technological revolution on welfare is interesting. When there is an unanticipated technological revolution, young agents are strictly better off, while old agents are strictly worse off if government intervention is not permitted. An appropriate transfer of income through government intervention enables the technological revolution to attain Pareto improvement allocation.

In the latter part, we explore the possibility that oscillatory equilibria are supported as perfect-foresight equilibria in the present framework with finitely lived agents and capital. Any oscillatory equilibrium involves the regime switch from an economy with both young and old capital in use into the one with only old capital in use. The regime switch involves the boom in the price of old capital, accompanied by zero investment in new capital. ${ }^{4}$ Although the price of old capital exhibits bubble-like behavior, the asset value reflects only economic fundamentals, but does not include the "rational bubbles" defined by Tirole (1985). ${ }^{5}$

We use a model of finitely lived agents although many vintage models are constructed in a setup with infinitely lived agents. One advantage of our model is to simplify the analysis in showing the behavior of the stock market and its interaction with economic fundamentals when

cycles in investment, as capital is periodically replaced. Boucekkine et.al (1997) (1998) characterize the dynamics of capital replacement and economic fluctuations under endogenous scrapping.

${ }^{4}$ Another perspective in the literature explains boom and crash in the stock market based on investors psychology or irrationality; see Bulow and Klemperer (1994), Lee (1998), and Zeira (1999).

5 Tirole (1985) develops a theoretical analysis linking economic growth with stationary bubbles that never explode in the model with finitely lived agents. See also Grossman and Yanagawa (1993) and Cozzi (1998). 
the technological revolution arrives.

We finally comment on the related literature. We differ from Hobjin and Jovanovic (2001) in two respects. First, we derive the endogenous obsolescence of old capital even by assuming that the productivity of old capital remains unchanged, in contrast to Hobjin and Jovanovic (2001) who assume that old capital becomes less productive when technological progress occurs. Second, we analyze the interaction among the stock market, capital accumulation, and growth. Laitner and Stolyarov (2003), while holding views close to ours, apply the idea of old capital obsolescence to the measurement problem of capital, succeeding in reconciling a fall in Tobin's Q with unchanging aggregate investment that arose during the period 1974-1984. Unlike theirs (2003), we develop an overlapping generations model, which seems to be more suitable for investigating the effects of an event that rarely occurs, such as revolutionary technological progress. In addition, the model allows us to study the effects of the revolution on the welfare of different generations.

The paper is organized as follows. Section 2 describes the model. Section 3 analyzes the equilibrium of the balanced-growth path. Section 4 investigates the effect of the technological change on the economy. Section 5 analyzes oscillatory equilibria when the boom in old capital arises. Section 6 provides concluding remarks.

\section{The Model}

We consider an economy consisting of an infinite sequence of two-period-lived, overlapping generations, plus an initial old generation. We let $t=0,1, \ldots$ index time. At each period a continuum of new generation appears with unit mass. Young agents are identical and endowed with one unit of labor, which is supplied inelastically in the labor market. The aggregate supply of labor at each period is unity. Old agents are retired. The initial old agents are each endowed with $I_{-2}(>0)$ units of capital that was invested in period -2 and $I_{-1}(>0)$ units of capital that was invested in period -1 . No agents other than the initial old ones have any endowment of capital or the final good at any period.

The preference of agents born at $t(\geq 0)$ is given by 


$$
\log C_{t}^{y}+\beta \log C_{t+1}^{o}
$$

where $C_{t}^{y}\left(C_{t+1}^{o}\right)$ denote consumption when they are young (old), and $\beta(0<\beta \leq 1)$ is the subjective discount factor. In the second period of life, each agent operates its own firm in order to produce the final good according to the technology

$$
Y_{t}=A K_{t}^{\gamma} L_{t}^{1-\gamma} \bar{k}_{t}^{1-\gamma}, \text { with } 0<\gamma<1
$$

where $Y_{t}$ is the final output, $K_{t}$ and $L_{t}$ are capital and labor employed by the firm, $\bar{k}_{t}$ is the average capital-labor ratio across firms which represents technological spillovers on the productivity of each firm, and $A$ is the total factor productivity that is assumed constant over time.

Agents have two means of saving the first-period income. The first is access to a constant-returns-to-scale technology that converts $x_{t}$ units of the final good into $a_{t+1} x_{t}$ efficiency units of capital between periods, where $a_{t+1}$ represents a technological parameter that is specific to the period-t investment. This assumption is meant to envisage a situation in which the technological change is embodied in new capital investment. The second is the purchase of existing capital in the secondary market from agents of the preceding generation.

Capital depreciates fully after two periods. ${ }^{6}$ It turns out that, at the beginning of period $t+1$, two types of capital may exist that differ in vintage, the capital good originally produced at period t, referred to as "young capital," and the one produced at $\mathrm{t}-1$, referred to as "old capital." After young capital is used as input for the final-good production, a portion $\delta(0 \leq \delta<1)$ of that capital depreciates physically, and the remaining $1-\delta$ survives and is sold in the secondary market as old capital. ${ }^{7}$ Young and old capital are perfect substitutes as inputs in the production function of the final good.

The labor market and the capital market are assumed to be perfectly competitive. Since all

6 The following fact might justify this assumption. Setting the annual depreciation of capital at $10 \%$, capital survives by about $12.2 \%$ after twenty years, and only about $1.5 \%$ after forty years

${ }^{7}$ The depreciation rate $\delta$ represents physical depreciation, and as will become clear below, should be distinguished from economic depreciation that arises from devaluations of capital. 
the firms are homogeneous, each of them chooses the same capital-labor ratio as the other. Since the total labor force is unity, each young agent earns the amount equal to the wage rate, denoted by $W_{t}$, to satisfy

$$
W_{t}=(1-\gamma) A K_{t},
$$

where $\bar{k}_{t}=K_{t} / L_{t}$ is used.

If agents invest one unit of the final good in the capital-production technology at period t, they produce $a_{t+1}$ efficiency units of capital at period $\mathrm{t}+1$, receive $a_{t+1} \gamma A$ as rents, and sell the remaining capital to agents of the subsequent generation. Letting $p_{t+1}$ denote the price of old capital measured in terms of physical unit, the gross rate of return from investing in young capital, denoted by $R_{t+1}^{\text {new }}$, is

$$
R_{t+1}^{n e w}=a_{t+1} \gamma A+(1-\delta) p_{t+1}
$$

Agents may alternatively purchase old capital in the secondary market. They purchase old capital at $p_{t}$ per physical unit, receive rent $a_{t} \gamma A$ in the next period and then liquidate it. Old capital is no longer of use after the second-round production. The gross rate of return from old capital, denoted by $R_{t+1}^{\text {old }}$, is

$$
R_{t+1}^{\text {old }}=\frac{a_{t} \gamma A}{p_{t}}
$$

If young and old capital are both held, agents should be indifferent in their regard. The no-arbitrage condition requires $R_{t+1}^{\text {new }}=R_{t+1}^{\text {old }}$, or equivalently

$$
a_{t+1} \gamma A+(1-\delta) p_{t+1}=\frac{a_{t} \gamma A}{p_{t}}
$$

\section{Equilibrium with Balanced-Growth Path}

We conduct a general equilibrium analysis of this economy. In this section we investigate the dynamic behavior of an economy in which new and old capital are both held. In fact, the economy can switch to an economy in which only one kind of capital will be in operation, but the analysis is left to Section 5 . 
From the preference given by (1), it is obvious that the aggregate savings, denoted by $S_{t}$, are given by

$$
S_{t}=s W_{t},
$$

where $s \equiv \beta /(1+\beta)$ is interpreted to be the saving rate.

Let $I_{t}$ denote the aggregate amount of the final good that is channeled to the production of new capital at period $t$. The market clearing in the good market requires that the aggregate savings equal the sum of the total investment in young capital, $I_{t}$, and the aggregate market value of the remaining old capital, $(1-\delta) p_{t} I_{t-1}$. It follows from (3) and (7) that

$$
s(1-\gamma) A K_{t}=I_{t}+(1-\delta) p_{t} I_{t-1} .
$$

The aggregate capital at the beginning of period $t+1$ is composed of young capital invested at period $\mathrm{t}$ and old capital initially invested at period $\mathrm{t}-1$ and traded in the secondary market at $\mathrm{t}$, given by

$$
K_{t+1}=a_{t+1} I_{t}+(1-\delta) a_{t} I_{t-1} .
$$

Let $\eta_{t} \equiv I_{t} / I_{t-1}$ denote the gross growth rate of young capital and let $\tilde{p}_{t} \equiv p_{t} / a_{t}$ denote the price of old capital measured in terms of efficiency unit, which we may call a "stock price."

Substituting (9) into (8) yields

$$
\eta_{t}=s(1-\gamma) A\left\{a_{t}+(1-\delta) \frac{a_{t-1}}{\eta_{t-1}}\right\}-(1-\delta) a_{t} \tilde{p}_{t} .
$$

By dividing both sides of (6) by $a_{t+1}$, we rewrite the no-arbitrage condition (6) by

$$
\gamma A+(1-\delta) \tilde{p}_{t+1}=\frac{\gamma A}{a_{t+1} \tilde{p}_{t}} .
$$

Each side of (11) measures the rate of return from capital in terms of efficiency units.

Here we define perfect-foresight equilibria by assuming that the technological parameter $a_{t}$ is constant over time, such that $a \equiv a_{t}=a_{t+1}=\ldots$.

\section{Definition 1}

Assume that the technological parameter $a_{t}$ is constant over time. Any perfect-foresight equilibrium of an economy where both young and old capital are held is a sequence of variables $\left\{\eta_{t}, \tilde{p}_{t}\right\}_{t=0}^{\infty}$ which satisfies (10), (11), and $\tilde{p}_{t} \geq 0$, given $\eta_{-1}>0$. 
First of all, we conduct a steady state analysis. The steady-state pair $\{\eta, \tilde{p}\}$ is characterized by the balanced growth path where investment, capital, and output grow at the rate $\eta$, while the price of old capital is constant over time, satisfying

and

$$
\begin{gathered}
\gamma A+(1-\delta) \tilde{p}=\frac{\gamma A}{a \tilde{p}}, \\
\eta=s(1-\gamma) a A\left(1+\frac{1-\delta}{\eta}\right)-(1-\delta) a \tilde{p} .
\end{gathered}
$$

We now analyze dynamic equilibria and obtain the following.

\section{Proposition 1}

A sufficient condition under which there exists a perfect-foresight equilibrium that converges to the balanced-growth path is

$$
\tilde{p}=\frac{-\gamma A+\sqrt{(\gamma A)^{2}+4(1-\delta) \gamma A / a}}{2(1-\delta)}<\frac{s(1-\gamma) A}{1-\delta} .
$$

Proof: In order to make the local analysis, we linearize the system (10) and (11) in the neighborhood of the steady state. Denoting the R.H.S. of (10) as $\lambda\left(\eta_{t-1}, \tilde{p}_{t}\right)$, we have

$$
\left[\begin{array}{l}
d \tilde{p}_{t+1} \\
d \eta_{t}
\end{array}\right]=\left[\begin{array}{cc}
-\gamma A / a(1-\delta)(\tilde{p})^{2} & 0 \\
-(1-\delta) a & \partial \lambda(\eta, \tilde{p}) / \partial \eta
\end{array}\right]\left[\begin{array}{l}
d \tilde{p}_{t} \\
d \eta_{t-1}
\end{array}\right] .
$$

Two eigenvalues of the Jacobian matrix are $-\frac{\gamma A}{a(1-\delta) \tilde{p}^{2}}$ and $\partial \lambda(\eta, \tilde{p}) / \partial \eta$. Rearrangement of (12) leads to $(1-\delta)(\tilde{p})^{2}=\frac{\gamma A(1-a \tilde{p})}{a}$. One eigenvalue satisfies $-\frac{\gamma A}{a(1-\delta) \tilde{p}^{2}}=-\frac{1}{1-a \tilde{p}}<-1$, since the above equality requires $0<\tilde{p}<1 / a$ if $\tilde{p}$ should be positively valued.

Next we examine another eigenvalue $\partial \lambda(\eta, \tilde{p}) / \partial \eta=-\frac{s(1-\gamma) a A(1-\delta)}{(\eta)^{2}}$. Rearranging (13) leads to $\eta^{2}-s(1-\gamma) a A(1-\delta)=\{s(1-\gamma) A-(1-\delta) \tilde{p}\} a \eta$. It is clear that $\eta^{2}>s(1-\gamma) a A(1-\delta)$ holds if $(1-\delta) \tilde{p}<s(1-\gamma) A$ is met. On the other hand, we obtain 
the equality of (14) from (12). If (14) is met, $-1<\partial \lambda(\eta, \tilde{p}) / \partial \eta<1$ holds.

One eigenvalue is greater and another is smaller than unity in absolute value. Given the initial condition $\eta_{-1}$, there exists a unique equilibrium path that converges to the balanced-growth path. Q.E.D.

Given that the price of old capital is constant over time, the equilibrium growth rate of investment converges to the balanced-growth path through endogenous fluctuations. A greater investment in new capital of the current period implies a greater stock of old capital purchased by agents of the next generation at the end of the subsequent period, which in turn tends to crowd out new capital investment made by the next generation. The counter-cyclical behavior between new capital and old capital is the driving force of endogenous fluctuations of economic growth.

Figure 1-1 and 1-2 illustrate the dynamic behavior of growth rates of investment, capital, and consumption, each of which converges to the balanced growth path through endogenous fluctuations. Capital and investment move in the same direction, but consumption and capital (or investment) move in the opposite direction. One can intuitively see this from

$$
\begin{aligned}
C_{t} & \equiv C_{t}^{y}+C_{t}^{o}=\left(W_{t}-S_{t}\right)+\left\{(1-\delta) p_{t} I_{t-1}+\gamma A K_{t}\right\} \\
& =\left\{(1-\gamma) A K_{t}-\left(I_{t}+(1-\delta) p_{t} I_{t-1}\right)\right\}+\left\{(1-\delta) p I_{t-1}+\gamma A K_{t}\right\}=A K_{t}-I_{t} .
\end{aligned}
$$

Given output $A K_{t}$, the aggregate consumption, $C_{t}$, is inversely related to investment in new capital investment.

\section{Technological Change}

In the 1990s the U.S. economy resurged along with the development of information technology (IT). The new technology promoted broader applications in computing and communications, and drastically changed the production process and life style. This technological revolution did not diffuse equally among all firms, but favored newly established firms over incumbent ones [e.g. Hobjin and Jovanovic (2001)]. In order to analyze this phenomenon, we consider a situation in which technological progress is embodied only in newly invested capital. Assume that at the beginning of period $\mathrm{T}$ people experience an 
unanticipated rise in the productivity of newly invested capital. We assume that $a_{T+1}=a_{T+2}=, \ldots,=a^{* *}>a_{T}=a^{*}$. Notice that the productivity of the existing old capital is not affected by the technological change. For later reference, we denote steady state values as depending on the technological parameter, such that $\tilde{p}(a)$ and $\eta(a)$, respectively.

Until period T-1, the steady state equilibrium is described as a pair $\left\{\tilde{p}\left(a^{*}\right), \eta\left(a^{*}\right)\right\}$, satisfying

and

$$
\begin{gathered}
a^{*}\left\{\gamma A+(1-\delta) \tilde{p}\left(a^{*}\right)\right\}=\frac{\gamma A}{\tilde{p}\left(a^{*}\right)}, \\
\eta\left(a^{*}\right)=s(1-\gamma) A\left(a^{*}+a^{*} \frac{1-\delta}{\eta\left(a^{*}\right)}\right)-(1-\delta) a^{*} \tilde{p}\left(a^{*}\right) .
\end{gathered}
$$

The technological revolution occurs at period $\mathrm{T}$, and equilibrium conditions are described as

$$
a^{* * *}\left\{\gamma A+(1-\delta) \tilde{p}_{T+1}\right\}=\frac{\gamma A}{\tilde{p}_{T}},
$$

and

$$
\eta_{T}=s(1-\gamma) A\left(a^{*}+a^{*} \frac{1-\delta}{\eta\left(a^{*}\right)}\right)-(1-\delta) a^{*} \tilde{p}_{T}
$$

Note that the new productivity value $a^{* *}$ appears only in (19). If, instead, the technological change would diffuse equally between new and old capital, the second term in the R.H.S. of (20) should be replaced by $(1-\delta) a^{* *} \tilde{p}_{T}$. We summarize interesting findings in the following.

\section{Result 1}

Assume that there is an unanticipated technological change at the beginning of period $\mathrm{T}$. The price of old capital measured in efficiency unit $\tilde{p}_{T}$ declines. The price of old capital measured in the physical unit $p_{T}\left(\equiv a_{T} \tilde{p}_{T}\right)$ also declines.

Proof: People anticipate the productivity change to be permanent, and $\tilde{p}_{T+1}=\tilde{p}\left(a^{* *}\right)$ follows. The backward induction of expectation leads to $\tilde{p}_{T}=\tilde{p}\left(a^{* * *}\right)$ through arbitrage. Additionally, as seen in (14), $\tilde{p}(a)$ is decreasing in $a$. The first part follows from this. The vintage-specific parameter of old capital remains $a^{*}$, and the price of old capital measured in physical unit becomes $a^{*} \tilde{p}\left(a^{* *}\right)$ that is smaller than $a^{*} \tilde{p}\left(a^{*}\right)$. The second part follows from this. Q.E.D.

The rise in productivity is embodied only in new capital, but not in old capital, and so agents 
invest more in new capital and less in old capital, followed by a fall in the price of old capital.

\section{Result 2}

Assume that there is an unanticipated technological change at the beginning of period $\mathrm{T}$. New capital investment grows faster than otherwise.

Proof: Since $\tilde{p}_{T-1}=\tilde{p}\left(a^{*}\right)>\tilde{p}_{T}=\tilde{p}\left(a^{* *}\right)$, comparing (18) and (20) leads to $\eta_{T}>\eta_{T-1}$. Q.E.D.

The fall in the old capital allows the greater amount of saving channeled into investment in new capital. The "substitution effect" reinforces investment in new capital.

After period $\mathrm{T}+1$, a rise in productivity is embodied in all the existing capital, and the price of old capital is expected to rise again. We obtain the following.

\section{Result 3}

Assume that there is an unanticipated technological change at the beginning of period T. The price of old capital measured in physical unit rises from period $\mathrm{T}+1 \mathrm{on}$.

Proof: It follows from (19) and the definition of $p(a)\{\equiv a \tilde{p}(a)\}$ that $(1-\delta)\{p(a)\}^{2}+\operatorname{a\gamma A} p(a)-a \gamma A=0$. Differentiating the above equation leads to $\frac{d p(a)}{d a}=\frac{\gamma A\{1-p(a)\}}{2(1-\delta) p(a)+a \gamma A}>0$, since the rearrangement of the above equation implies $(1-\delta)\{p(a)\}^{2}=a \gamma A\{1-p(a)\}$ which requires $0<p(a)<1$, if $p(a)$ should be positively valued. Q.E.D.

From period $\mathrm{T}+1$ on, the no-arbitrage condition are described as (19). At period $\mathrm{T}+1$, the market clearing condition in the good market is given by

$$
\eta_{T+1}=s(1-\gamma) A\left(a^{* *}+a^{*} \frac{1-\delta}{\eta_{T}}\right)-(1-\delta) a^{* *} \tilde{p}\left(a^{* *}\right) .
$$

Comparing (20) and (21), we find that an increase in $a$ has two opposite effects on the growth rate of new capital investment. On the one hand, the improvement in the efficiency of capital increases output and saving, while on the other hand, it also increases the value of old capital. 
The former tends to promote investment in new capital, whereas the latter tends to shrink it. The total effect on $\eta_{T+1}$ is ambiguous. From period $\mathrm{T}+2$ on, the market clearing condition in the good market is given by

$$
\eta_{T+i+1}=s(1-\gamma) A\left(a^{* *}+a^{* *} \frac{1-\delta}{\eta_{T+i}}\right)-(1-\delta) a^{* *} \tilde{p}\left(a^{* *}\right) \quad i=1,2,3, \ldots .
$$

We next turn to the analysis of an anticipated technological change. The emergence of the internet, although there were initially only a few internet-based investment opportunities, in the eyes of many observers the changes signaled fast future productivity growth and an increased potential for obsolesce of existing capital. Before the upcoming introduction of a new technology, news about its arrival will affect investment and the price of the existing capital.

We study the simplest case in which technological change that comes at $\mathrm{T}$ is forecasted one period in advance. We examine the effect of the anticipated technological change by assuming that at the beginning of period T-1 people anticipates the arrival of technological change anticipates at $\mathrm{T}$. We summarize main properties in the following two results

\section{Result 4}

Assume that the arrival of technological change at period $\mathrm{T}$ is anticipated at the beginning of period T-1. The price of old capital measured in efficiency unit $\tilde{p}_{T-1}$ rises. The price of old capital measured in the physical unit $p_{T-1}$ rises. After period T, prices of old capital measured in efficiency and physical units behave in the same manner as the case of the unanticipated shock.

Proof: We first examine the third part. Since period T when the information about the technological shock is revealed, it is straightforward to see that the behavior of old price in efficiency unit is the same between the anticipated and the unanticipated changes. No-arbitrage condition at period $\mathrm{T}$ requires

$$
\gamma A+(1-\delta) \tilde{p}_{T+1}=\frac{\gamma A}{a^{* *} \tilde{p}_{T}}
$$

If people anticipate the steady state price of old capital to be sustained from period $\mathrm{T}+1$ on, the equality $\tilde{p}_{T}=\tilde{p}_{T+1}=\ldots \equiv \tilde{p}\left(a^{* *}\right)$ follows to satisfy (23).

When the technological change is anticipated one period in advance, people at period T-1 
invest in assets by conjecturing $\tilde{p}_{T}=\tilde{p}\left(a^{* * *}\right)$. No-arbitrage condition at T-1 requires

$$
a^{* *}\left\{\gamma A+(1-\delta) \tilde{p}_{T}\right\}=\frac{\gamma A}{\tilde{p}_{T-1}}
$$

Of course, $\tilde{p}\left(a^{* *}\right)$ satisfies

$$
a^{* *}\left\{\gamma A+(1-\delta) \tilde{p}\left(a^{* *}\right)\right\}=\frac{\gamma A}{\tilde{p}\left(a^{* *}\right)} .
$$

It follows from (30), (31), $\tilde{p}_{T}=\tilde{p}\left(a^{* *}\right)$ that

$$
p_{T-1} \equiv a^{*} \tilde{p}_{T-1}=a^{* *} \tilde{p}\left(a^{* *}\right) \equiv p\left(a^{* *}\right),
$$

and with $a^{*}<a^{* *}$ and Result 3 .

$$
p\left(a^{*}\right)<p_{T-1}=p\left(a^{* *}\right)
$$

follows. The first part follows from this.

The inequality $\tilde{p}\left(a^{*}\right)<\tilde{p}_{T-1}$ follows since $p\left(a^{*}\right)=a^{*} \tilde{p}\left(a^{*}\right)<a^{*} \tilde{p}_{T-1} \equiv p_{T-1}$ follows from equations (26), (27), and $a^{*}<a^{* *}$. The second part follows from this. Q.E.D.

In the case of an anticipated shock, the stock market reacts before the shock actually arrives. Result 4 suggests that the path of investment in new capital will differ between an anticipated case and an unanticipated case. We obtain the following.

\section{Result 5}

If the arrival of technological change at period $\mathrm{T}$ is anticipated one period in advance, the growth rate of new capita investment is smaller at period T-1 and greater at period $\mathrm{T}$ than otherwise.

Proof: First we show the former part of the Result. The growth rates of investment at T-1 $\eta_{T-1}^{A}$ and $\eta_{T-1}^{U}$ satisfy,

$$
\begin{aligned}
& \eta_{T-1}^{A}=s(1-\gamma) A\left\{a^{*}+(1-\delta) \frac{a^{*}}{\eta_{T-2}^{A}}\right\}-(1-\delta) p_{T-1}^{A} \\
& \eta_{T-1}^{U}=s(1-\gamma) A\left\{a^{*}+(1-\delta) \frac{a^{*}}{\eta_{T-2}^{U}}\right\}-(1-\delta) p_{T-1}^{U}
\end{aligned}
$$

where the superscripts A and U denote the case of anticipated technological shock and unanticipated one, respectively. Since the economy is in the steady state until t-2, 
$\eta_{T-2}^{U}=\eta_{T-2}^{A}\left(=\eta^{*}\right)$, Result 3 shows that $p_{T-1}^{U}=p\left(a^{*}\right)<p\left(a^{* *}\right)=p_{T-1}^{A}$, then $\eta_{T-1}^{A}<\eta_{T-1}^{U}\left(=\eta^{*}\right)$. Now we show $\eta_{T}^{A}>\eta_{T}^{U}$. Growth rate of investment at period $\mathrm{T}$ is described by

$$
\begin{aligned}
& \eta_{T}^{A}=s(1-\gamma) A\left\{a^{*}+(1-\delta) \frac{a^{*}}{\eta_{T-1}^{A}}\right\}-(1-\delta) p_{T}^{A} \\
& \eta_{T}^{U}=s(1-\gamma) A\left\{a^{*}+(1-\delta) \frac{a^{*}}{\eta_{T-1}^{U}}\right\}-(1-\delta) p_{T}^{U}
\end{aligned}
$$

We obtain $\eta_{T}^{A}>\eta_{T}^{U}$ since $p_{T}^{U}=p_{T}^{A}\left(=a^{*} \tilde{p}\left(a^{* *}\right)\right)$ and $\eta_{T-1}^{A}<\eta_{T-1}^{U}\left(=\eta^{*}\right)$. Q.E.D.

When the technological change arrives, there occurs a greater investment boom if it is anticipated beforehand than not. In the case of anticipated technological change, young agents at period T-1 foresee that technological progress at period T makes capital newly invested at period T-1 obsolete and its valuation low. They find new capital investment at T-1 less attractive and hence old capital more attractive even there are no productivity shocks at $\mathrm{T}-1$. The consequent smaller market valuation of old capital at period $\mathrm{T}$ allows a greater amount of saving channeled into investment in new capital than the case of an unanticipated case.

It is useful to review the net national product (NNP) in the present model. We define the net national product (NNP) as

$$
W_{t}+I_{t-1}\left\{\gamma A a_{t}+(1-\delta) a_{t} \tilde{p}_{t}-1\right\}+(1-\delta) a_{t-1} \tilde{p}_{t-1} I_{t-2}\left(\frac{\gamma A}{\tilde{p}_{t-1}}-1\right)
$$

where the first term represents the labor income and the second and third terms the net income from new and old capital, respectively. On the other hand, the depreciation of capital comprises two components, such that

$$
\left\{1-(1-\delta) a_{t} \tilde{p}_{t}\right\} I_{t-1}+(1-\delta) a_{t-1} \tilde{p}_{t-1} I_{t-2} .
$$

The first term represents the depreciation of new capital and the second term the depreciation of old capital. Interestingly, new capital depreciates in two ways, first through the physical depreciation captured by $\delta$ and second through the economic depreciation represented by the fall in $\tilde{p}_{t}$. It is this aspect of capital depreciation that Laitner and Stolyarov (2003) concentrate on in constructing Tobin's Q. Equations (32) and (33) imply that the gross national product (GNP) is $Y_{t}$. It follows from Result 1, (32), and (33) that, when the technological change 
arrives, capital depreciates faster, NNP declines, but GNP does not change.

The market value and the book value of capital are equal because the existing capital is necessarily traded in the secondary market in our model with two-period-lived agents. However, if the model is extended to allow for longer-lived agents or firms, the firms may keep holding the existing capital. If firms do not revise asset values of capital downward in response to the technological change, depreciation of capital would finally be undervalued on national accounts.

Finally in this section we examine the impact of technological change on welfare. We focus on the welfare analysis in terms of the possible conflict of interest among different generations. ${ }^{8}$ In the face of the unanticipated shock, we calculate the lifetime consumption of each generation. The young-age consumption of the generation $t$ is proportional to wage income, and is

$$
C_{t}^{y}=\frac{\beta}{1+\beta} W_{t}=\frac{(1-\gamma) \beta A}{1+\beta}\left\{a_{t} I_{t-1}+(1-\delta) a_{t-1} I_{t-2}\right\} .
$$

The old-age consumption is

$$
C_{t}^{o}=\gamma A\left\{a_{t+1} I_{t}+(1-\delta) a_{t} I_{t-1}\right\}+(1-\delta) a_{\mathrm{t}+1} \tilde{p}_{t+1} I_{t} .
$$

The first term represents the rent from capital, and the second term the gain from selling capital to the subsequent generation. In a growing economy, the benefits of technological change are greater over time. However, Result 1 suggests that people of some generation incurs capital losses from holding old capital and may be worse off.

We examine the lifetime consumption of the two generations who are alive when the technological change arrives. For agents born at $\mathrm{T}$, the young-age consumption remains unchanged, but the old-age consumption changes to

$$
C_{T+1}^{o}=\gamma A\left\{a^{* * *} I_{T}+(1-\delta) a^{*} I_{T-1}\right\}+(1-\delta) a^{* *} \tilde{p}\left(a^{* *}\right) I_{T} .
$$

When $a$ rises, $I_{T}$ increases (Result 2) and $p(a)\{\equiv a \tilde{p}(a)\}$ rises (Result 3). The young generation is better off. On the other hand, for agents born at T-1, the young-age consumption remains unchanged, but the old-age consumption changes to

$$
C_{T}^{o}=\gamma A\left\{a^{*} I_{T-1}+(1-\delta) a^{*} I_{T-2}\right\}+(1-\delta) a^{*} \tilde{p}\left(a^{* *}\right) I_{T-1} .
$$

In the face of the unanticipated technological progress, the old generation finds the decline in

8 While a number of works recently argue the effect of technological progress on the welfare in terms of increasing income inequality between skilled and unskilled workers (e.g. Jovanovic (1998) and Caselli (1999)). 
the price of old capital to fall (Result 1). The old generation is worse off.

It is straightforward to see that people that are born from period $\mathrm{T}+1$ on are better off. Old agents incur capital losses by holding old capital because technological progress leads to economic obsolescence in old capital. This finding suggests that when a rise in productivity is embodied only in new capital, there may be a conflict of interest between people who enjoy the benefits of holding new capital and who incur capital losses from holding old capital.

In the case of the anticipated technological change, the conflict of interest arises in the different way. Briefly speaking, when the technological change is anticipated at T-1, it affects $p_{T-1}$ as well $p_{T}$. Since the rise in price of old capital at T-1 increases the consumption level of generation T-2 and decreases that of generation T-1, lump-sum transfer between generation T-2 and T-1 is also needed for Pareto Improvement allocation.

If the transfer of income is permitted through government intervention, however, the welfare of agents born at both periods T-1 and T may be improved. Intuitively, an increase in productivity from period $\mathrm{T}+1$ on will lead to an increase in output after period $\mathrm{T}+1$ while output of before period $\mathrm{T}$ remains unchanged. We obtain the following.

\section{Proposition 2}

When there is technological change, there exists a lump-sum transfer of income that implements a Pareto improvement.

Proof: We mainly prove the case of unanticipated technological change, and briefly state on the anticipated case. As in the proof of Result 5, the superscripts A and U denote the case of anticipated technological shock and unanticipated one, respectively. Variables without superscripts denote the case without any technological change.

First we show that the output at period $\mathrm{T}$ remains the same as that when the technological change does not happen. The output at period $\mathrm{T}, Y_{T}$, is shown to be $Y_{T}^{U}=A K_{T}^{U}=A a^{*}\left\{I_{T-1}^{U}+(1-\delta) I_{T-2}^{U}\right\}=C_{T}^{Y U}+C_{T}^{o U}+I_{T}^{U}$

Since $I_{T-1}^{U}$ and $I_{T-2}^{U}$ are not affected by the technological change, $Y_{T}^{U}=Y_{T}$. Since $Y_{T}^{U}=Y_{T}=C_{T}^{Y}+C_{T}^{o}+I_{T}$, an allocation $C_{T}^{Y U}=C_{T}^{Y}, C_{T}^{O Y}=C_{T}^{O}$, and $I_{T}^{U}=I_{T}$ can be realized by an appropriate transfer scheme. Second we show that the consumption level of 
generation $\mathrm{T}$ at period $\mathrm{T}+1, C_{T+1}^{O U}$ can be increased. The total output at period $\mathrm{T}+1, Y_{T+1}^{U}$, is $Y_{T+1}^{U}=A K_{T+1}^{U}=A\left\{a^{* *} I_{T}^{U}+(1-\delta) a^{*} I_{T-1}^{U}\right\}=C_{T+1}^{Y U}+C_{T+1}^{o U}+I_{T+1}^{U}$, which is greater than $Y_{T+1}$ Therefore, an appropriate transfer by government can achieve Pareto-improving allocation.

In the case of an anticipated technological change, an additional transfer is needed at period T-1, since the change affects $p_{T-1}^{A}$ as well $p_{T}^{A}$. At period T-1, a transfer similar to one described above can set $C_{T-1}^{Y A}=C_{T-1}^{Y}, C_{T-1}^{O A}=C_{T-1}^{O}$, and $I_{T-1}^{A}=I_{T-1}$. The same transfer scheme at period $\mathrm{T}$ as one in the unanticipated case achieve Pareto-improving allocation. Q.E.D.

\section{Oscillatory Equilibria}

In this section we study the possibility of a regime switch from an economy with both new capital and old capital active to an economy with only one type of capital active.

If the equilibrium switches to an economy in which only new capital is in operation, old capital would become completely obsolete. However, this is impossible so long as $\delta<1$. Hence we focus on a regime change in which the equilibrium switches to an economy in which no new capital investment occurs and only old capital is in operation. Intuitively, this regime switch involves an appreciation in old capital and crowding out of new capital investment.

Throughout this section we assume that the vintage-specific parameter is constant over time, such that $a \equiv a_{t}=a_{t+1}=\ldots$. Assume that there is a break period $T(0 \leq T<\infty)$ when new capital investment is not made. Until period T-1, then any equilibrium sequence remains to be described by (10) and (11).

Since all the saving should be channeled to the purchase of old capital at period T, the market clearing in the good market requires $S_{T}=(1-\delta) p_{T} I_{T-1}$ since $I_{T}=0$. By incorporating $\eta_{T}=0$ into (10), we obtain

$$
s(1-\gamma) A\left(1+\frac{1-\delta}{\eta_{T-1}}\right)=(1-\delta) \tilde{p}_{T} .
$$

If equilibria satisfy (38), agents have to prefer old capital to new capital to satisfy $R_{T+1}^{\text {new }} \leq R_{T+1}^{\text {old }}$, or equivalently

$$
\gamma A+(1-\delta) \tilde{p}_{T+1} \leq \frac{\gamma A}{a \tilde{p}_{T}}
$$


The asset price at the break period $\tilde{p}_{T}$ should be sufficiently high to satisfy (38) so that the anticipated price $\tilde{p}_{T+1}$ should be sufficiently low to satisfy the inequality (39).

We need some elaboration to describe the equilibrium at period $\mathrm{T}+1$ because $I_{T}=0$ implies that the secondary market for old capital is not opened at period $\mathrm{T}+1$. At period $\mathrm{T}+1$ investment in new capital absorbs all the saving. The equilibrium condition is simply given by

$$
s(1-\gamma) A K_{T+1}=I_{T+1} .
$$

Note that $K_{T+1}=a(1-\delta) I_{T-1}$; the outstanding stock of capital at period T+1 succeeds to only capital that has originally been invested at period T-1. It is impossible to write the equilibrium condition at period $\mathrm{T}+1$ in terms of $\eta_{t}$ since $I_{T}=0$. If both new and old capital are held from $\mathrm{T}+2$ on, (10) and (11) again describe equilibrium conditions. Here we characterize equilibria more completely by allowing for the possibility of the regime change.

\section{Definition 2}

Assume that the technological parameter $a_{t}$ is constant over time. (I) When $T \rightarrow \infty$, any perfect-foresight equilibrium is a sequence of variables $\left\{\eta_{t}, \tilde{p}_{t}\right\}_{t=0}^{\infty}$ satisfies (10), (11) with equality, given $\eta_{-1}>0$, for any $t$. (II) When there is a $T<\infty$, any perfect-foresight equilibrium is a sequence of variables $\left\{\eta_{t}, \tilde{p}_{t}\right\}_{t=0}^{\infty}$ satisfies (10), (39) with equality for any $t$ except for $t=T, T+1$, satisfies (38), (39), and $\eta_{T}=0$ for $t=T$, and $\eta_{T+1} \rightarrow \infty$ for $t=T+1$, given $\eta_{-1}>0$.

Figure 2 illustrates the dynamics of the price of old capital in the $\left(\tilde{p}_{t}, \tilde{p}_{t+1}\right)$ plane. Any of price paths that lie apart from the steady state price $\tilde{p}$ oscillates. This figure shows that at period $\mathrm{T}$ the wealth constraint (10) binds with $\eta_{T}=0$ and is replaced by (38). At this moment the no-arbitrage condition can be violated.

Since the secondary market for capital does not exist at period $\mathrm{T}+1$, the backward induction of expectation formation does not work between $\mathrm{T}$ and $\mathrm{T}+1$. It turns out that the behavior of the economy before the break period $\mathrm{T}$ is not constrained by the behavior after $\mathrm{T}$. On regime switch, what connects the economies before and after the break period $\mathrm{T}$ is only the outstanding capital 
stock $K_{T+1}$ that is inherited from investment in period T-1 to satisfy $K_{T+1}=(1-\delta) a I_{T-1}$, and hence the violation of the no arbitrage condition can be consistent with rational behavior of agents. Given the "new" initial condition $K_{T+1}$, the economy restarts. A new sequence of the price of old capital $\left\{\tilde{p}_{t}\right\}_{t=T+2}^{S}(S \leq \infty)$ is defined irrespective of the past sequence, showing either oscillatory path again or a convergence to the steady state.

Given the same parameter values and initial conditions, the equilibrium can exhibit either a convergence to the balanced-growth path or oscillatory equilibria, depending on the investors' expectations. If agents anticipate a constant price of old capital over time, the self-fulfilling expectation dictates the equilibrium to converge to the balanced-growth path. However, if agents anticipate the stock market boom, the equilibrium exhibits an oscillatory behavior. Although the price of old capital exhibits bubble-like behavior, the asset value reflects only economic fundamentals, but does not include the "rational bubbles" defined by Tirole (1985).

The standard overlapping-generation models with capital that depreciates at constant rate excludes explosive paths as violating the no-arbitrage condition at the instant when bubbles absorb all the savings and hence are inconsistent with rational behaviors of investors if bubbles should be held. ${ }^{9}$ The framework with finitely lived agents and capital, however, allows paths that show the bubble-like behavior of asset prices to be consistent with perfect-foresight equilibria. Since capital survives only a finite period and hence the composition of capital changes over time, the aggregate market value of capital need not continue to grow faster over time.

We illustrate the behavior of an oscillatory equilibrium. Before doing so, we have to check some properties of oscillatory equilibria. Note that the inequality (39) may restrict the parameter space under which oscillatory equilibria exist. We have the following.

\section{Result 6}

A necessary condition for the existence of any oscillatory equilibria is $s(1-\gamma) a A<1-\delta$. The

\footnotetext{
${ }^{9}$ If an asset in question should be rolled over forever, any equilibrium with explosive bubbles could be sustainable only when the asset could be purchased at higher prices by successive generations that earn even higher wage income. This is impossible since then the market value of the bubble should exceed the aggregate savings.
} 
price of old capital at the break period T, $p_{T}$, must satisfy $\frac{s(1-\gamma) A}{1-\delta}<p_{T} \leq 1 / a$.

Proof: Rearranging (39), we obtain $\tilde{p}_{T+1}^{e} \leq \frac{1}{1-\delta} \gamma A\left(\frac{1}{a \tilde{p}_{T}}-1\right)$. Since any expected price $\tilde{p}_{T+1}^{e}$ should be nonnegative, the inequality $\tilde{p}_{T} \leq 1 / a$ follows. Rearranging (38) yields $\frac{s(1-\gamma) A(1-\delta)}{\eta_{T-1}}=(1-\delta) \tilde{p}_{T}-s(1-\gamma) A$. The initial condition $\eta_{T-1} \equiv \frac{I_{T-1}}{I_{T-2}}>0$ has to be positive, and $\frac{s(1-\gamma) A}{1-\delta}<\tilde{p}_{T}$ has to be met. This inequality and $\tilde{p}_{T} \leq 1 / a$ jointly imply that $s(1-\gamma) a A<1-\delta$ is a necessary condition for any oscillatory equilibria to be viable. The latter inequalities are immediate. Q.E.D.

In addition, we have more restrictions on parameter values according to when the break period arrives.

\section{Result 7}

Assume that $s(1-\gamma) a A<1-\delta$ holds. A oscillatory equilibrium with $\mathrm{T}=0$ exists if $\eta_{-1} \geq \frac{s(1-\gamma) a A(1-\delta)}{1-s(1-\gamma) a A}$. A oscillatory equilibrium with $\mathrm{T}=1$ exists if $0<\eta_{-1} \leq s(1-\gamma)(1-\delta) /\left\{\frac{\gamma(1-\delta)}{1-\delta+a \gamma A}+\frac{s(1-\gamma)(1-\delta)}{1-\delta-s(1-\gamma) a A}-s(1-\gamma)\right\}$.

Proof: We first prove the earlier part. Result 6 reveals that, in any oscillatory equilibrium, $\frac{s(1-\gamma) A}{1-\delta}<\tilde{p}_{0} \leq 1 / a$ must hold at $\mathrm{T}=0$. We wish to prove that such an equilibrium can be constructed if $\eta_{-1} \geq \frac{s(1-\gamma) a A(1-\delta)}{1-s(1-\gamma) a A}$

Define a function $\Gamma(\eta) \equiv \frac{s(1-\gamma) A}{1-\delta}[1+(1-\delta) / \eta]$. It is easy to show that $\Gamma(\eta)=\frac{s(1-\gamma) A}{1-\delta}$ as $\eta \rightarrow \infty$, and $\Gamma(1 / a)=\frac{s(1-\gamma) a A(1-\delta)}{1-\delta-s(1-\gamma) a A}$. Since $\Gamma(\eta)$ is a monotone decreasing function, $\frac{s(1-\gamma) A}{1-\delta}<\Gamma(\eta) \leq 1 / a$ is satisfied if $\eta \geq \frac{s(1-\gamma) a A(1-\delta)}{1-\delta-s(1-\gamma) a A}$ holds. Hence, an equilibrium satisfying 
$s(1-\gamma) A\left[1+(1-\delta) / \eta_{-1}\right]=(1-\delta) \tilde{p}_{0}$ and $\frac{s(1-\gamma) A}{1-\delta}<\tilde{p}_{0} \leq 1 / a$ can be constructed if $\eta_{-1} \geq \frac{s(1-\gamma) a A(1-\delta)}{1-\delta-s(1-\gamma) a A}$ is met.

Second, we prove the latter part. We can show that $\frac{s(1-\gamma) A}{1-\delta}<\tilde{p}_{1} \leq 1 / a$ must hold in the same way as the earlier part. We obtain $(1-\delta) a \tilde{p}_{0}=\frac{\gamma A(1-\delta)}{(1-\delta) \tilde{p}_{1}+\gamma A}$ from (11) and $\eta_{0}=\frac{s(1-\gamma) A(1-\delta)}{(1-\delta) \tilde{p}_{1}-s(1-\gamma) A}$ from (38), and so $(1-\delta) a \tilde{p}_{0}+\eta_{0}$ is decreasing in $\tilde{p}_{1}$, taking the value within $\left[\frac{\gamma A(1-\delta)}{(1-\delta) / a+\gamma A}+\frac{s(1-\gamma) A(1-\delta)}{(1-\delta) / a-s(1-\gamma) A}, \infty\right)$. Equation (10) must hold at $\mathrm{t}=0$, and rearranging it yields $\eta_{-1}=\frac{s(1-\gamma) a A(1-\delta)}{(1-\delta) a \tilde{p}_{0}+\eta_{0}-s(1-\gamma) a A}$. Since $(1-\delta) a \tilde{p}_{0}+\eta_{0}$ has the range described above, we obtain the range of $\eta_{-1}$ as $\left(0, s(1-\gamma)(1-\delta) /\left\{\frac{\gamma(1-\delta)}{1-\delta+a \gamma A}+\frac{s(1-\gamma)(1-\delta)}{1-\delta-s(1-\gamma) a A}-s(1-\gamma)\right\}\right] . \quad$ If $\eta_{-1}$ lies in this interval, we can construct an equilibrium defined by $\left\{\eta_{0}, \tilde{p}_{0}, \tilde{p}_{1}\right\}$ satisfying $\eta_{0}>0, \tilde{p}_{0} \geq 0$, and $\frac{s(1-\gamma) A}{1-\delta}<\tilde{p}_{1} \leq 1 / a$. Otherwise such an equilibrium cannot be constructed. Q.E.D.

It is easy to construct an oscillatory equilibrium with the break period at $\mathrm{T}=1$. The good market clearing condition at period $t=0$ becomes

$$
\eta_{0}=s(1-\gamma) A a\left(1+\frac{1-\delta}{\eta_{-1}}\right)-(1-\delta) a \tilde{p}_{0} .
$$

The no-arbitrage condition at period 0 implies

$$
(1-\delta) \tilde{p}_{1}+\gamma A=\frac{\gamma A}{a \tilde{p}_{0}} .
$$

Finally, the good market clearing condition at the break period $(\mathrm{T}=1)$ implies

$$
s(1-\gamma) A\left(1+\frac{1-\delta}{\eta_{0}}\right)=\tilde{p}_{1} .
$$

Equations (41), (42), and (43) yield an equilibrium sequence, $\left\{\tilde{p}_{0}, \tilde{p}_{1}, \eta_{0}\right\}$, as long as the condition presented in Result 6 is met.

We conduct a numerical analysis. We set $A=2.6, a=1, \gamma=.3, \delta=0$, and 
$\beta=.99^{20}=0.817$. We take twenty years for one period. Additionally, we set $I_{-2}=1$ and $I_{-1}=0.186$, and so $\eta_{-1}=0.186$. The steady-state pair $\left\{\tilde{p}^{*}, \eta^{*}\right\}$ is $\{0.575,1.034\}{ }^{10}$ Figure 3-1 through 3-5 illustrates the dynamic behavior over the periods covering before and after the break period. In all the figures the "white" dot illustrates the convergent path with $\tilde{p}_{t}=\tilde{p}^{*}$ for all t's, and the "black" dot an oscillatory path.

\section{Period 0: Outset of the belief in the boom}

Agents, based on a "sunspot", believe that the stock market boom will happen next period. At the current period agents anticipate the smaller price of old capital than unless the boom is anticipated. As shown in Figure 3-1, we have $\tilde{p}_{0}=0.441<\tilde{p}^{*}=0.575$. the smaller market value of old capital enables more saving to be channeled into investment in new capital (Figure $3-4)$. The stock market capitalization relative to GNP, $p_{0} I_{-1} / Y_{-1}$, is smaller than the one in the convergent path (Figure 3-2).

\section{Period 1: Break Period: Boom in the Stock Market}

The price of old capital rises (Figure 3-1), and accordingly the stock market capitalization relative to GNP rises (Figure 3-2), accompanied by zero investment in new capital (Figure 3-4) and the greater consumption (Figure 3-5). The stock market boom is associated with consumption boom.

\section{Period 2: Recession}

The stock market capitalization relative to GNP becomes zero because the secondary market for old capital is not opened. The level of output drops sharply, as captured by a negative growth rate of output (Figure 3-3). The decline in output arises from the smaller available stock ( $K_{2}=I_{0}<K_{1}=I_{0}+I_{-1}$ ), which arises because any investment in new capital has not been made at period 1. Consumption also declines (Figure 3-5). All the saving is channeled to

${ }^{10}$ If we take one period as twenty years, we get $\eta_{-1}{ }^{1 / 20}=0.919$. Then the average annual growth rate is $-8.1 \%$. Similarly, the steady-state annual growth rate corresponding to $\eta^{*}$ is $0.2 \%$.. 
investment in new capital and investment grows faster. Note that the growth rate of investment in new capita is infinite although it is not plotted in Figure 3-4.

\section{Period 3: Bottom}

Based on a "sunspot", agents recur to forming a "normal" expectation. The old capital is quoted at the steady-state price $p^{*}=0.575$ (Figure 3-1). Surprisingly, the output level is even smaller than the previous period, as captured by a negative growth rate of output (Figure 3-3). This reflects the fact that newly invested capital at the previous period only accounts for the outstanding stock of capital. We have $K_{3}=I_{2}$ that is smaller than $K_{2}=I_{0}$.

\section{Period 4: Symptom of Recovery}

The economy begins to recover from the recession and converge to the balanced-growth path through endogenous fluctuations (Figure 3-5).

Noteworthy, a persistent recession comes after the stock market boom ends. The stock market boom occurs at the sacrifice of investment in new capital. The available stock of capital declines over a number of periods, and prolongs the recession.

\section{6: Conclusion}

We construct a growth model of overlapping generations based on vintage capital and derive several findings that could not be obtained otherwise. When investment-specific technological change arrives, the economy converges to a new balanced growth path with a higher growth rate of output through endogenous fluctuations, but stock market capitalization, although even though it finally grows, initially shrinks to the extent that new capital producers do not go public. Technological change leads to faster depreciation of capital.

We find a different prediction from the standard theory about the behavior of the stock market and its interaction with economic fundamentals that drive fluctuations in the economy. The stock market may show perverse behavior as a predictor of the future economic fundamentals. This is because the market for new capital is often "missing". Although the 
technological revolution leads to the rise in the relative price of new to old capital, we may observe only the devaluation of old capital in the public market. Additionally, as we showed in the analysis of oscillatory equilibria, we may misread the rise in the relative price as a future economic boom.

Future research may take several directions. One important task is to exploit consequences of faster depreciation of existing capital when technological change arrives. ${ }^{11}$ As argued in Section 4, if firms keep holding old capital, the national account may underestimate depreciation of capital and overestimate NNP. This theoretical finding gives an important suggestion on how to evaluate the existing capital when technological changes occur. We might obtain a similar result on the contribution of the investment-specific technological change on economic growth as that of Greenwood et al (1997).

An analysis of the impacts of divergence between the market value and book value of existing capital held by incumbent firms may give a hint to explain the conservative behavior of these firms relative to new firms [e.g. Hobjin and Jovanovic (2001)]. Assume that the model is extended to allow for longer-lived agents or firms. When the technological change arrives, firms will attempt to adjust the book value of the capital only slowly relative to market evaluation and may undervalue the asset value of new investment.

Throughout this paper we have focused on the effect of exogenous technological change. It is interesting to introduce the process of technology adoption into the model. One way is to introduce in some way the notion of the match between new technology and skilled workers into the model. Another way is to apply the possible conflict of interest among different generations regarding the arrival of new technology, as studied in the last part of Section 4. If the young take the initiative in adopting new technology, the economy will tend to adopt new technology, whereas if the old have the initiative, the economy may not adopt it. If new capital is produced by a the subsidiary of a company whose main office may be described by the aggregate production function, the age distribution of the company may influence the choice of new technology.

We have assumed that young capital and old capital are perfect substitutes. It is of interest to

${ }^{11}$ See the important work by Laitner and Stolyarov (2003). 
extend the model to allow for imperfect substitutability of different vintages of capital. The technological revolution may be interpreted as an extreme case when the elasticity of substitution becomes infinity. The more general framework may be useful to make for a richer analysis.

Government policies may perversely influence economic growth. Tax reform, such as the dividend tax reduction advocated by the Bush administration, can increase the price of old capital, thereby deterring economic growth.

One interesting theoretical topic for investigation is whether the stationary bubbles defined by Tirole can exist in our model. Weil (1990) demonstrates that under production technology similar to ours, the stationary bubbles will exist. Furthermore, the introduction of the notion of vintage capital into the original Diamond model is an important extension. Although the non-linear property of the Diamond model may make the analysis challenging, this line of investigation is worth pursuing. 


\section{References}

Benhabib, J. and A. Rustichini (1991),“Vintage capital, investment, and growth,” Journal of Economic Theory 55, 323-339.

Bulow, J. and P. Klemperer (1994), "Rational frenzies and crashes," Journal of Political Economy 102, 1-23.

Boldrin, M., and D. K. Levine (2001),“Growth cycles and market crashes,” Journal of Economic Theory 96, 13-39.

Boucekkine, R., M. Germain, and O. Licandro (1997), "Replacement echoes in the vintage capital growth model," Journal of Economic Theory 74, 333-348.

Boucekkine, R. M Germain, O. Licandro, and A. Magnus (1998), "Creative destruction, investment volatility, and the average age of capital," Journal of Economic Growth 3, 361-384.

Boucekkine, R. F. d. Rio, and O. Licandro (1999), "Endogenous vs exogenously driven fluctuations in vintage capital models," Journal of Economic Theory 88, 161-187.

Caballero, R. J. and M. L. Hammour (1994),"The cleansing effect of recessions," American Economic Review 84, 1350-1368.

Caballero, R. J. and M. L. Hammour (1996), "On the timing and efficiency of creative destruction," Quarterly Journal of Economics 111, 805-852.

Caselli, F. (1999), “Technological revolutions,” American Economic Review 89, 78-102.

Chari, W. V. and H. Hopenhayn (1991), "Vintage human capital, growth, and the diffusion of new technology,“ Journal of Political Economy 99, 1142-1165.

Cozzi, G. (1998), “Culture as a bubble,” Journal of Political Economy 106, 376-394.

Diamond, P. (1965), "National debt in a neoclassical growth model," American Economic Review 55, 1126-1150.

Fershtman, C. and K. M. Murphy, and Y. Weiss (1996), "Social status, education, and growth," Journal of Political Economy 104, 108-132.

Greenwood, J., Z.Hercowitz, and P. Krusell (1997), "Long-run implications of investment-specific technological change," American Economic Review 87, 342-362.

Grossman, G. M. and N. Yanagawa (1993), “Asset bubbles and endogenous growth,” Journal of 
Monetary Economics 31, 3-19.

Hobjin, B. and B. Jovanovic (2001), "The Information-technology revolution and the stock market: evidence," American Economic Review 91, 1203-1220.

Jovanovic, B. (1998), "Vintage capital and inequality," Review of Economic Dynamics 1, 497-530.

Kremer, M. and J. Thomson (1998), “Why isn't convergence instantaneous? Young workers, old workers, and gradual adjustment," Journal of Economic Growth 3, 5-28.

Laitner, J. and D. Stolyarov (2003), "Technological change and the stock market,” American Economic Review 93, 1240-1267.

Lee, I. H. (1998), "Market crashes and informational avalanches," Review of Economic Studies 65, 741-759.

Tirole, J. (1985), “Asset bubbles and overlapping generations,” Econometrica 53, 1499-1528.

Weil, P. (1990), "On the possibility of price decreasing bubbles," Econometrica 58, 1467-1474.

Zeira, J. (1999), “Informational overshooting, booms, and crashes,” Journal of Monetary Economics 43, 237-57. 
Figure 1-1: Evolution of $\eta_{t}=I_{t} / I_{t-1}$

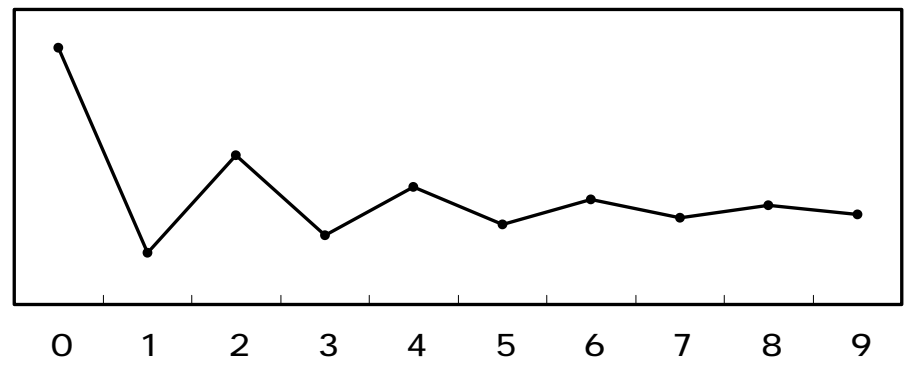

Figure 1-2: Evolutions of $K_{t} / K_{t-1}$ and $C_{t} / C_{t-1}$

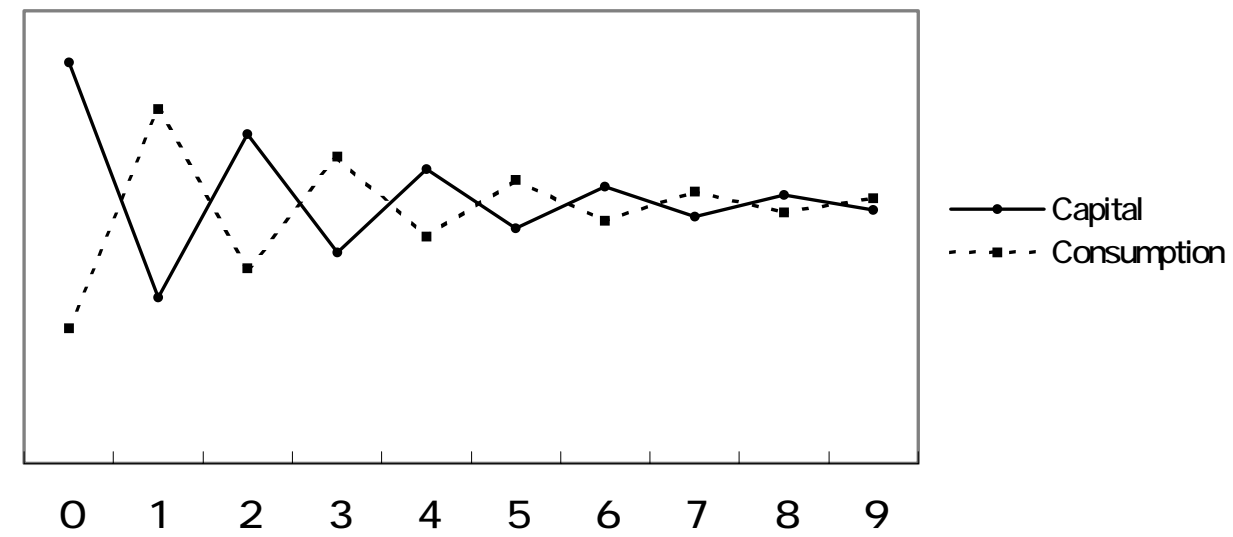


Figure 2 Oscillatory Price Path

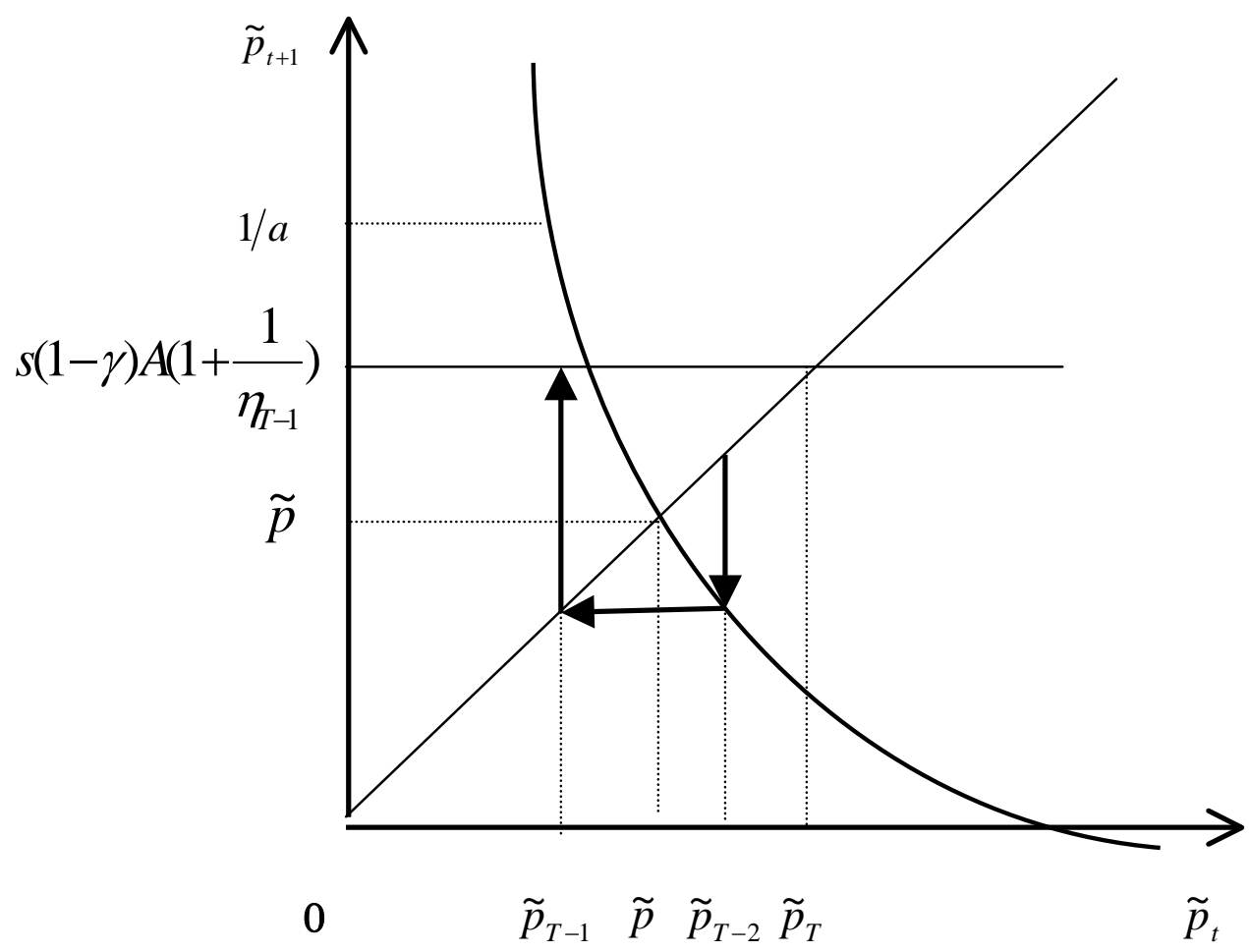


Figure 3-1

Price of Old Capital: $\tilde{p}_{t}\left(=p_{t}\right)$

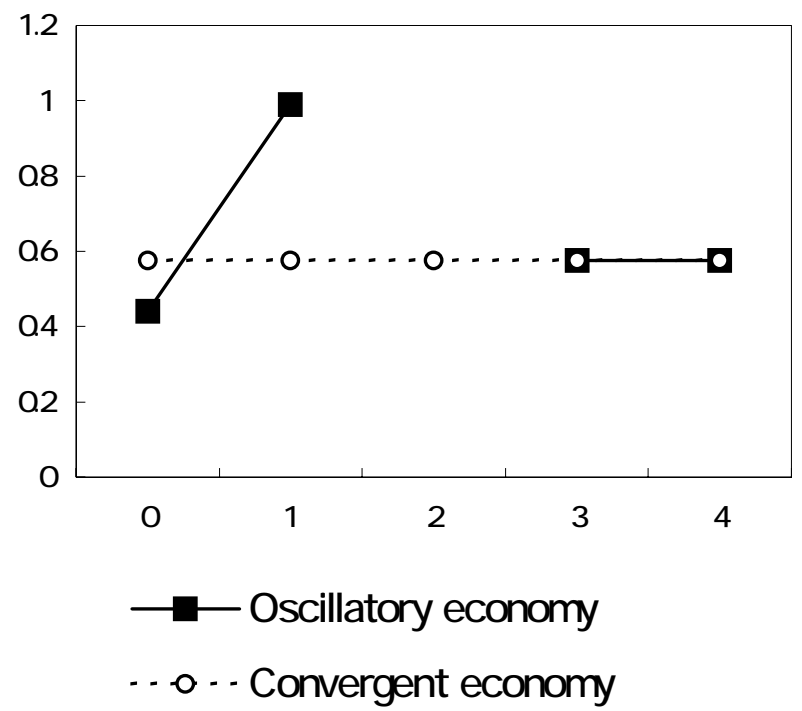

The price $\tilde{p}_{2}$ is not defined for the oscillatory economy since there is no old capital at period 2.

Figure 3-2

Market Capitalization/GNP

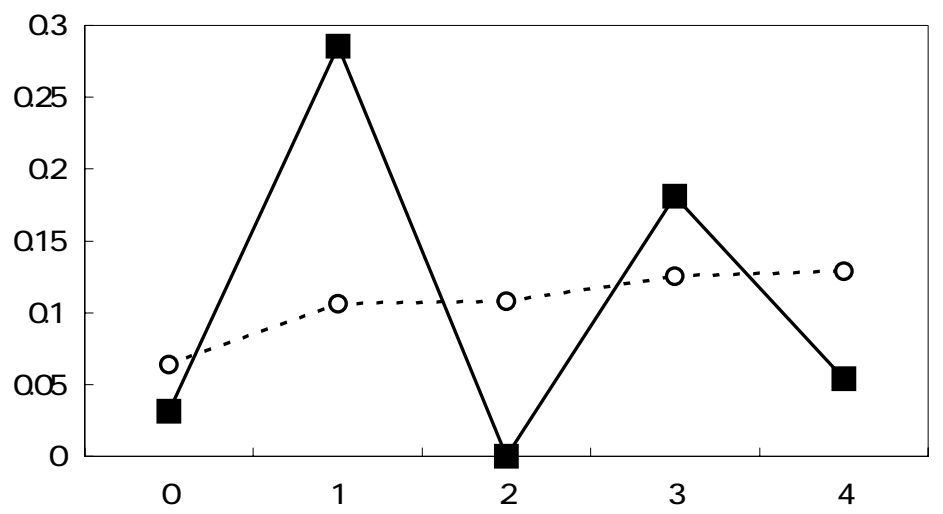


Figure 3-3

Annual Growth Rate of Output

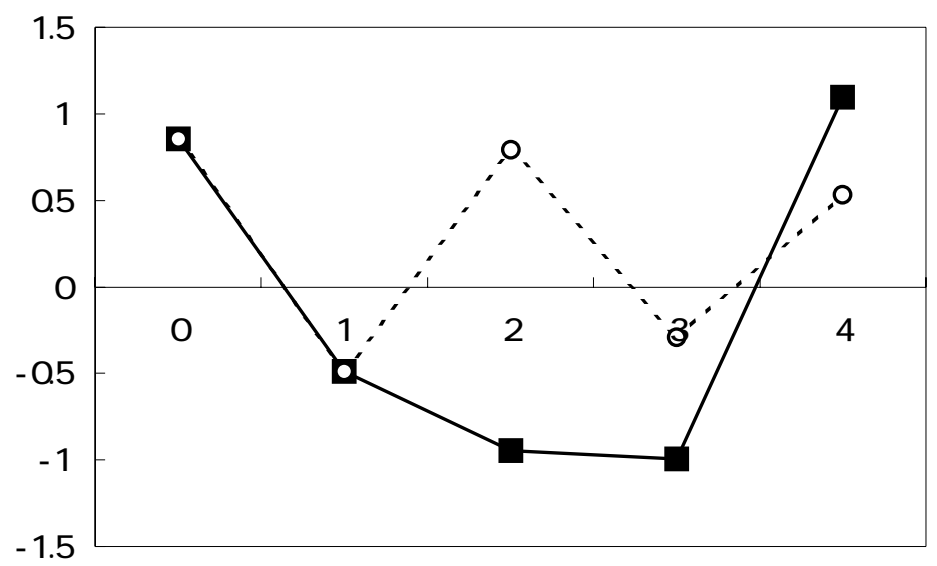

Figure 3-4

Annual Growth Rate of New Capital investment

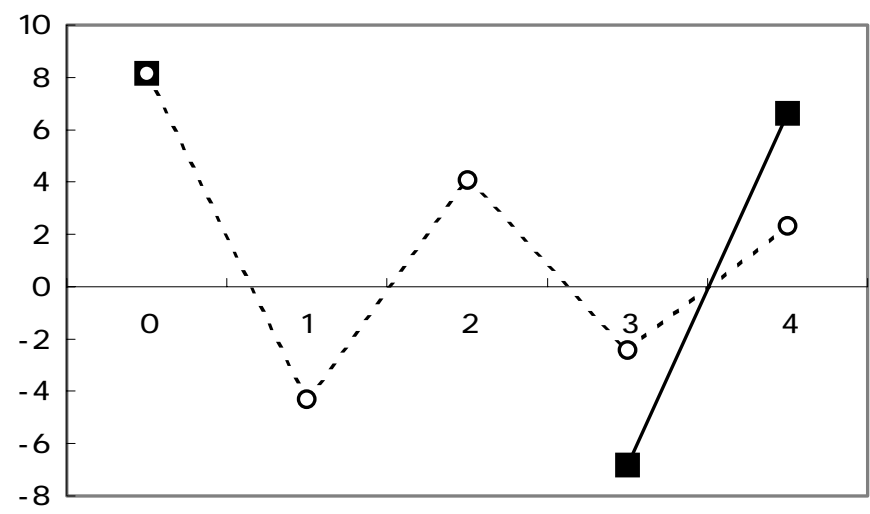

Growth rates of new capital investment at periods 1 and 2 are not defined for the oscillatory economy. 
Figure 3-5:

Annual Growth Rate of Consumption

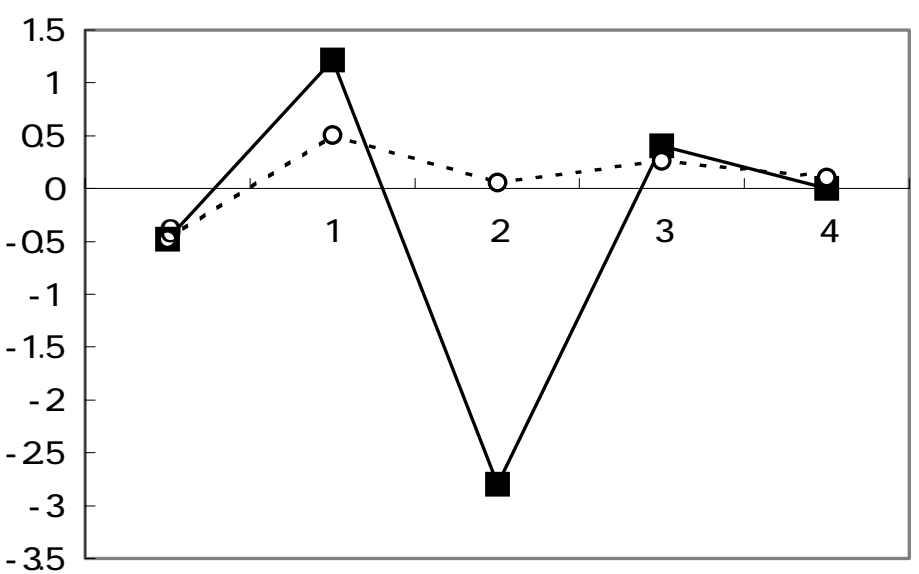

